\title{
PERANCANGAN BUKU ENSIKLOPEDIA EKOLOGI \& LINGKUNGAN TENTANG MANUSIA DAN LINGKUNGANNYA UNTUK ANAK USIA 9-12 TAHUN
}

\author{
Gladys Dian Prameswari Sutanto, \\ Benny Rahmawan Noviadji, \\ Christyan Budi Susilo. \\ Institut Informatika Indonesia (IKADO), Surabaya. \\ choi.gladys@gmail.com
}

\begin{abstract}
Abstrak
Kehidupan mahluk hidup tidak lepas dari peran lingkungan sebagai tempat tinggal. Lingkungan air dan udara memegang peran penting dalam menjaga stabilitas ekologi dan kehidupan mahluk hidup. Namun peradaban manusia sekarang merusak lingkungan diantaranya limbah pabrik, asap kendaraan, kebakaran hutan serta banjir yang mengakibatkan bencana dan merugikan semua pihak. Penanaman edukasi sejak dini sangat penting untuk membangun karakter anak agar mencintai dan melindungi lingkungan. Melalui metode pengumpulan data yaitu wawancara dan penyebaran kuesioner menyatakan bahwa saat ini anak-anak masih kurang peduli terhadap lingkungan sekitar dan kurangnya media pembelajaran mengenai pemahaman akan ekologi dan lingkungan. Pembuatan ensiklopedia ekologi dan lingkungan dibuat menjadi 3 buku yaitu tumbuhan dan hewan serta hubungannya dengan manusia sebagai buku pertama. Air dan udara serta hubungannya dengan manusia sebagai buku kedua. Bencana alam yang terjadi akibat alam sendiri dan yang terjadi akibat ulah manusia sebagai buku ketiga. Melalui buku ensiklopedia bercerita dan bergambar ini akan memberikan daya tarik anak-anak terhadap pemahaman dan pengenalan ekologi dan lingkungan kehidupan disekitar manusia.
\end{abstract}

Kata kunci: Ilustrasi, Ensiklopedia, Ekologi, Lingkungan.

\begin{abstract}
The lives of all living being can't be separated from the environment's role as a place to live. Environment, water and air play important roles in maintaining ecological stability and the life of living beings. However, human civilization is now damaging the environment, with industrial waste, vehicle smoke, forest fires, and floods which result in disasters that harm all parties. Educating children from an early age is very important in order to build their character so that they grow to love and protect the environment around them. Through interview data collection method and questionnaires, it is stated that at this moment children don't care about the environment around them
\end{abstract}


enough and that the media to educate children about ecology and the environment is lacking. The making of this ecology and environment encyclopedia will be made into three separate books which are: plants, animals and their relation to human being as the first book. Water and air and its relation to human beings as the second. Natural disasters that occur because of nature itself and disasters that occur because of human beings as the third.. Through this story-telling illustrated encyclopedia, this book will give children's interest toward introduction and understanding ecology and the environment around them.

Keywords: : illustration, encyclopedia, ecology, environment.

\section{PENDAHULUAN}

Kehidupan manusia tidak bisa dipisahkan dari lingkungannya, baik lingkungan alam maupun lingkungan sosial. Manusia bernapas memerlukan udara dari lingkungan sekitar, manusia makan, minum, menjaga kesehatan dan aktivitas lainnya memerlukan lingkungan. Lingkungan dan makhluk hidup memiliki hubungan timbal balik. Ilmu yang mempelajari hubungan timbal balik antara organisme-organisme hidup dengan lingkungannya disebut ekologi. Maka dari itu, ekologi sangatlah penting bagi keberlangsungan kehidupan makhluk hidup. Indonesia merupakan negara kepulauan terbesar yang memiliki 13.466 pulau yang mengisi wilayahnya. Indonesia juga merupakan negara dengan hutan hujan tropis terbesar ketiga dan merupakan negara dengan biodeversitas (keanekaragaman hayati) terbesar kedua setelah Brasil. Namun sangat disayangkan bahwa dibalik kekayaan alam yang melimpah tersebut Indonesia masih banyak mengalami masalah-masalah lingkungan hidup yang bisa dibilang cukup parah.

Untuk mendukung program pelestarian lingkungan yang telah diberikan oleh pemerintah, sangatlah penting mengadakan pembelajaran sejak dini tentang ekologi dan lingkungan. Sebab di jaman modern ini, manusia menjadi kurang peduli akan lingkungan sekitar. Apalagi bila tidak dimulai dari sejak dini, masa depan akan sangat terancam. Menanamkan edukasi mengenai ekologi dan lingkungan akan memberikan dampak yang baik bagi perkembangan sikap, pengetahun, keterampilan dan daya cipta yang diperlukan anak dalam 
menyesuaikan diri dengan lingkungan dan untuk pertumbuhan serta perkembangan selanjutanya.

Pendekatan pembelajaran yang baik untuk anak adalah dengan menggunakan buku, karena membaca memberi rangsangan yang optimal bagi perkembangan anak-anak usia sekolah. Membaca merupakan salah satu fungsi tertinggi dari otak manusia dan dapat dikatakan bahwa semua proses belajar didasarkan pada kemampuan membaca.

Dari penelitian berupa wawancara dan pembagian kuesioner yang telah dilakukan serta melihat fenomena dan permasalahan yang terjadi dapat ditemukan inti permasalahan sebagai berikut: a) Kondisi ekologi dan lingkungan yang kurang baik di Indonesia; b) Masyarakat yang masih kurang benar-benar paham mengenai ekologi dan lingkungan; c) Keberadaan dan jumlah buku ekologi dan lingkungan yang jarang ditemui; d) Kurangnya pengetahuan anak terhadap ekologi dan lingkungan.

Ruang lingkup yang dikerjakan dalam penelitian tugas akhir ini adalah: a) Perancangan tiga seri buku ensiklopedia sebagai media utama dan sebagai media informasi kepada anak-anak sekolah dasar, orang tua dan masyarakat umum; b) Perancangan media merchandise sebagai media pendukungnya; c) Perancangan media promosi untuk masyarakat luas. Tujuan dari perancangan ini memberikan pengetahuan mengenai ekologi dan lingkungan kepada anak-anak usia 9-12 tahun dalam bentuk ilustrasi atau visual yang mudah dipahami sehingga anak dapat mengerti, mengenal, peduli dan cinta akan ekologi dan lingkungan hidup sekitar serta dapat mengaplikasikan ke dalam kehidupan sehari-hari.

\section{KAJIAN TEORI}

\section{Teori Ensiklopedia}

Ensiklopedia menurut Ahira dalam www.anneahira.com/ensiklopedia merupakan kumpulan dari penjelasan kata-kata yang berisi tentang informasi secara luas, lengkap dan mudah untuk dipahami tentang kumpulan ilmu pengetahuan atau cabang ilmu tertentu yang disusun berdasarkan huruf atau abjad yang kemudian dicetak ke dalam bentuk buku. Pada dasarnya, ensiklopedia merupakan perkembangan dari kamus, sehingga banyak orang menilai 
ensiklopedia ini sama halnya dengan kamus. Berbeda dengan kamus, penjelasan yang ada pada ensiklopedia ini lebih detail adanya dan juga lebih mendalam dari kata yang ingin dicari. Sedangkan kamus, berisikan tentang definisi suatu kata yang ingin dicari berdasarkan sudut pandang linguistik yang bisa dikatakan kamus merupakan pengertian yang berisi tentang sinonim dari suatu kata saja. Dengan begitu, sudah jelas ensiklopedia ini memiliki kelebihan tersendiri daripada kamus.

\section{Teori Ekologi dan lingkungan}

Penggunaan Istilah Ekologi diperkenalkan oleh Ernest Haeckel berasal dari bahasa Yunani, yaitu oikos = Tempat Tinggal (rumah), logos = Ilmu/telaah . Sehingga Ekologi adalah ilmu yang mempelajari hubungan timbal balik antara mahluk hidup dengan sesamanya dan dengan lingkungnya (Ramli, 1989: 2). Seorang Ahli Ekologi, Odum (1993) menyatakan bahwa ekologi adalah suatu studi tentang struktur dan fungsi ekosistem atau alam dan manusia sebagai bagiannya. Struktur ekosistem menunjukkan suatu keadaan dari sistem ekologi pada waktu dan tempat tertentu termasuk keadaan densitas organisme, biomassa, penyebaran materi (unsur hara), energi, serta faktor-faktor fisik dan kimia lainnya yang menciptakan keadaan sistem tersebut.

Pembahasan ekologi tidak lepas dari pembahasan ekosistem dengan berbagai komponen penyusunnya yaitu faktor abiotik dan biotik. Faktor abiotik antara lain suhu, air, kelembaban, cahaya dan tipografi, sedangkan faktor biotik adalah makhluk hidup yang terdiri dari manusia, hewan, tumbuhan dan mikroba. Ekologi juga berhubungan erat dengan tingkatan-tingkatan organisasi makhluk hidup yaitu populasi, komunitas dan ekosistem yang saling mempengaruhi dan merupakan suatu sistem yang menunjukkan kesatuan.

Lingkungan menurut Kamus Besar Bahasa Indonesia (2005: 877) adalah keadaan sekitar yang mempengaruhi perkembangan dan tingkah laku makhluk hidup. Segala sesuatu yang ada di sekitar manusia yang mempengaruhi perkembangan kehidupan manusia baik langsung maupun tidak langsung juga merupakan pengertian lingkungan. Lingkungan hidup dapat didefinisikan sebagai daerah tempat suatu makhluk hidup berada, keadaan atau kondisi yang melingkupi suatu makhluk hidup, keseluruhan keadaan yang meliputi suatu makhluk hidup atau sekumpulan makhluk hidup (Supardi, 2009: 11). 


\section{METODE PENELITIAN}

Penelitian data dilakukan untuk mendukung proses perancangan. Metode penelitian yang dilakukan yaitu melalui: 1) Mengidentifikasi fenomena dan permasalahan; 2) Studi kompetitor dan studi komparator. Dalam perancangan ini, diambil beberapa contoh buku untuk mendapatkan analisis data studi banding dengan buku kompetitor meliputi buku yang berjudul Ensiklopedia Cilik: Laut, Ensiklopedia: Hewan Unik dan Ensiklopedia Mini: Hewan Indonesia. Sedangkan untuk studi komparator meliputi buku yang berjudul Ensiklopedia Anak Hebat: Bumi dan Ensiklopedia Cerdas: Dunia Anak; 3) Hasil wawancara mendalam terhadap narasumber yaitu 2 guru IPA Sekolah Dasar dan 2 supervisor toko buku. Penyebaran kuesioner yang ditujukan kepada remaja sampai dewasa lanjut serta melakukan focus group diskusi pada anak-anak berusia 9-12 tahun; 4) Studi literatur dan teori yang berhubungan dengan penelitian; 5) Hasil dari kuesioner untuk mengetahui keinginan audiens serta menemukan permasalahan.

\section{HASIL DAN PEMBAHASAN}

Lingkungan dan makhluk hidup memiliki hubungan timbal balik. Ilmu yang mempelajari hubungan timbal balik antara organisme-organisme hidup dengan lingkungannya disebut ekologi. Sedangkan, kajian tentang kenyataan dan upaya yang harus dilakukan oleh manusia untuk mengelola lingkungan hidup sesuai dengan peran dan fungsinya agar dapat mendukung perikehidupan dan meningkatkan kesejahteraan manusia serta makhluk hidup lainnya disebut ilmu lingkungan.

Dari berbagai inti permasalahan yang telah diungkapkan, maka diperlukan buku ensiklopedia ekologi dan lingkungan yang berbeda dengan buku ensiklopedia pada umumnya, dengan ilustrasi yang lebih menarik, perwarnaan yang playful dan vibrant. Cerita disajikan dengan menarik perhatian anak dengan adanya empat karakter utama. Buku ini menceritakan Profesor singa yang datang dari masa depan dan 3 orang anak yang akan menikmati liburan dengan bermain dan belajar bersama mengenal ekologi serta lingkungan sekitar kehidupan manusia. Dengan adanya ilustrasi dan cerita yang menarik dalam buku ensiklopedia ini, diharapkan anak-anak dapat mengenal ekologi dan lingkungan kehidupan dengan baik dan 
dapat mengaplikasikan dalam kehidupan sehari-hari untuk menjaga lingkungan sekitar.

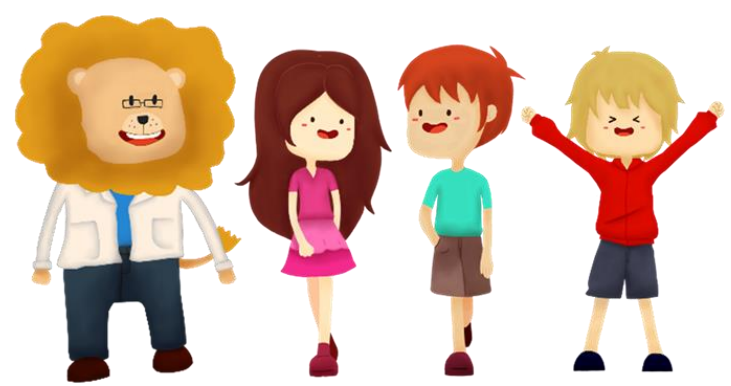

Gambar 1. Karakter utama Professor Lion, Hana, Nico dan Jhonatan

Sumber: Dokumentasi Penulis

Proses perancangan media utama yaitu tiga seri buku ensiklopedia ekologi dan lingkungan, seri pertama mengenai tumbuhan dan hewan serta hubungannya dengan manusia, seri kedua mengenai air dan udara serta hubungannya dengan manusia dan seri ketiga mengenai bencana alam. Setelah itu, dilakukan pembuatan storyboard sehingga dapat diketahui karakter-karakter yang diperlukan. Karakter utama terdiri dari tiga anak (Hana, Nicho dan Jonathan) dan seekor singa (Profesor Lion). Untuk dapat menggambarkan dengan baik cerita tersebut, disinilah kegunaan environment berada. Berikut ini adalah contoh environment buku jilid pertama:

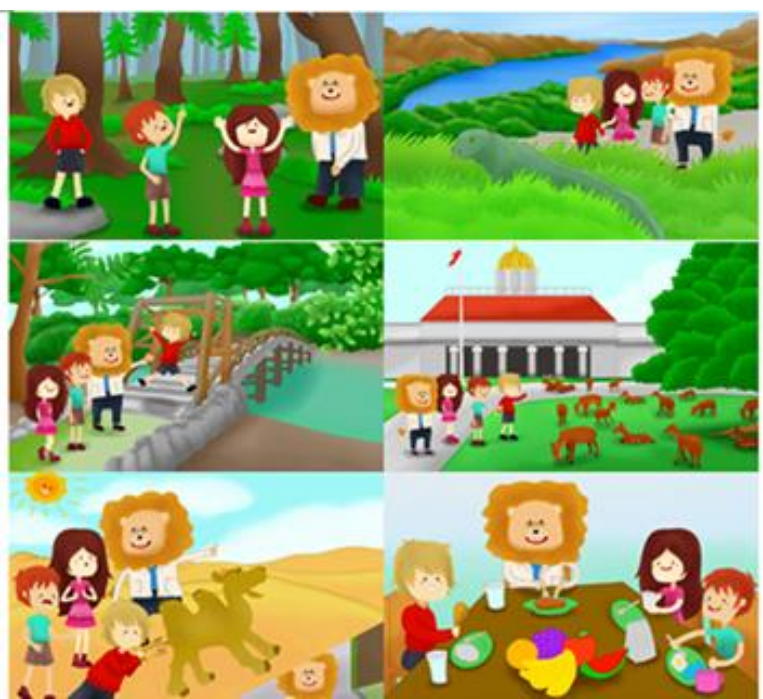

Gambar 2. Environment buku pertama Sumber: Dokumentasi Penulis 


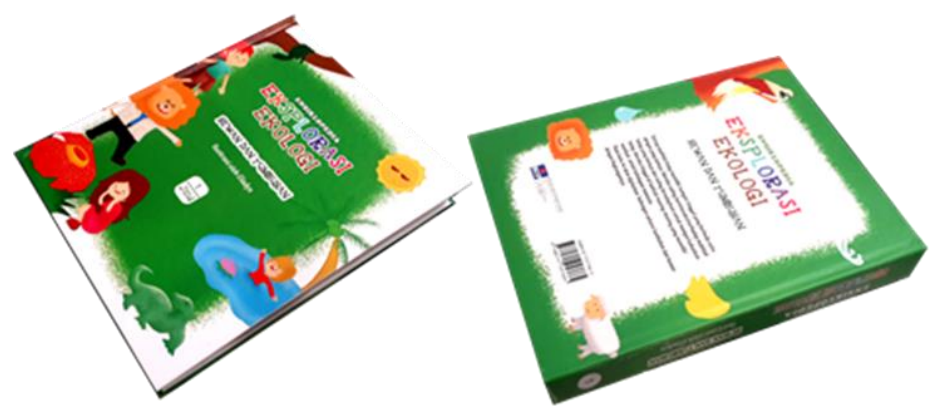

Gambar 3. Cover depan \& belakang buku pertama Sumber: Dokumentasi Penulis

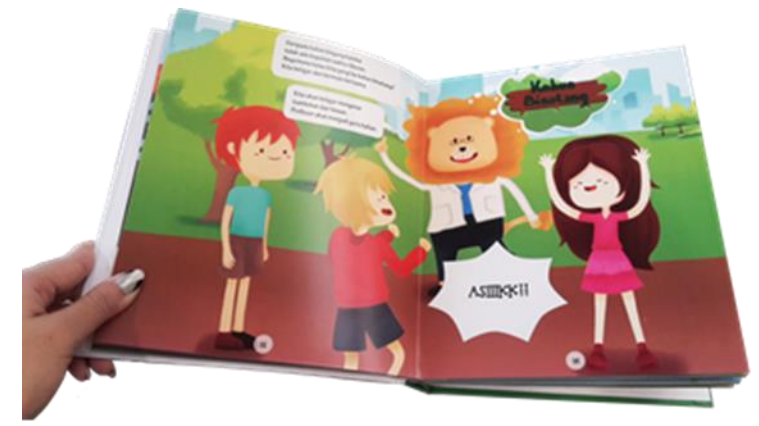

Gambar 4. Simulasi buku pertama Sumber: Dokumentasi Penulis

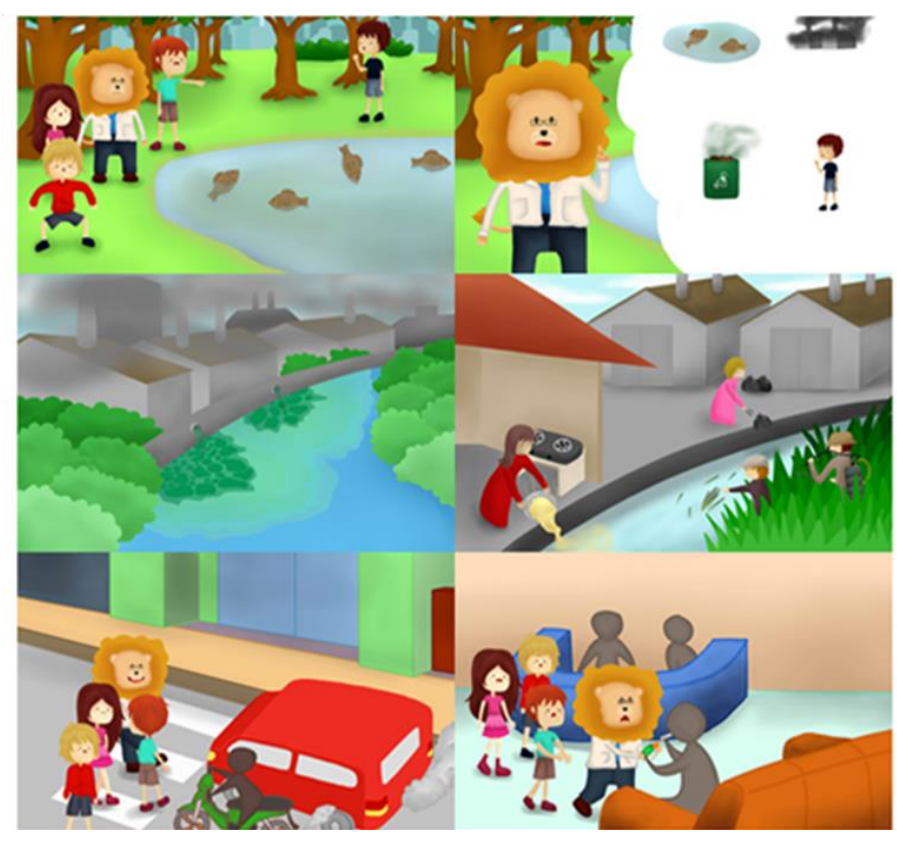

Gambar 5. Environment buku kedua

Sumber: Dokumentasi Penulis 


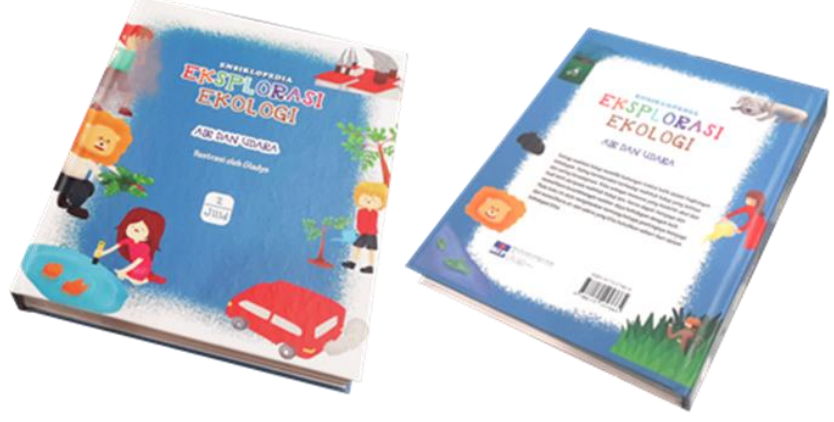

Gambar 6. Cover depan \& belakang buku kedua Sumber: Dokumentasi Penulis

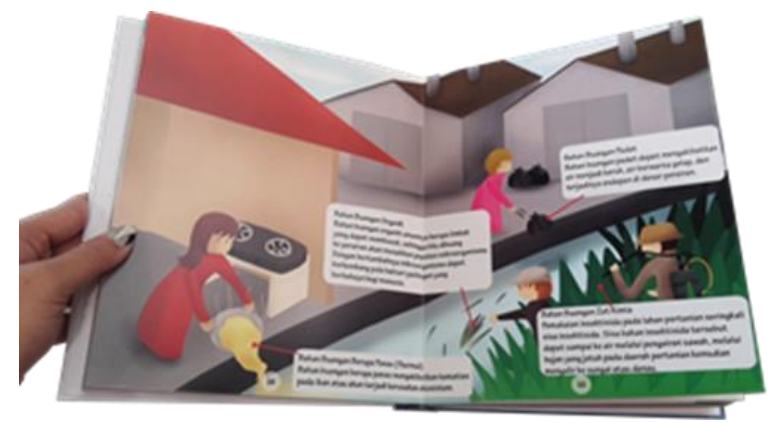

Gambar 7. Simulasi buku kedua

Sumber: Dokumentasi Penulis

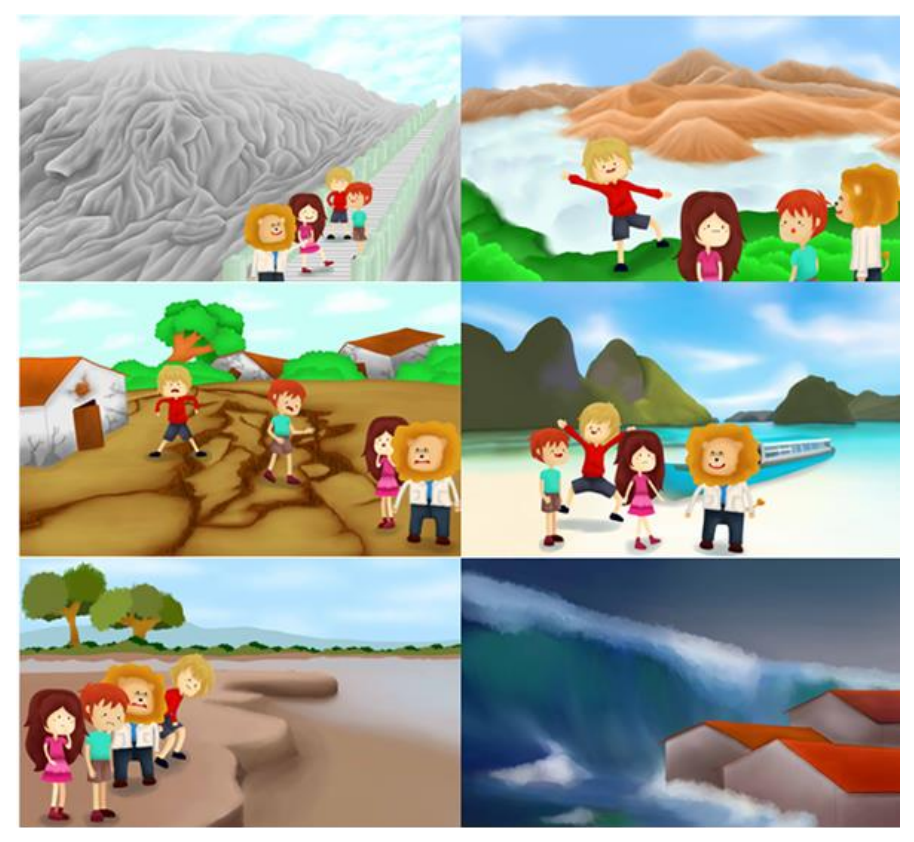

Gambar 8. Environment buku ketiga

Sumber: Dokumentasi Penulis 

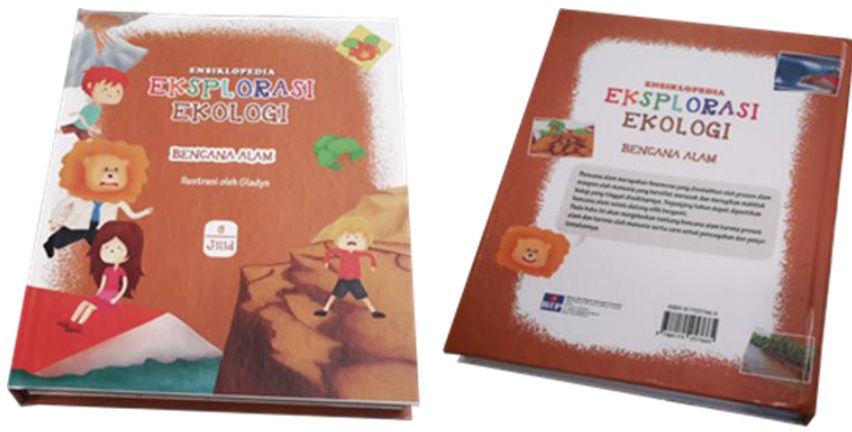

Gambar 9. Cover depan \& belakang buku ketiga

Sumber: Dokumentasi Penulis

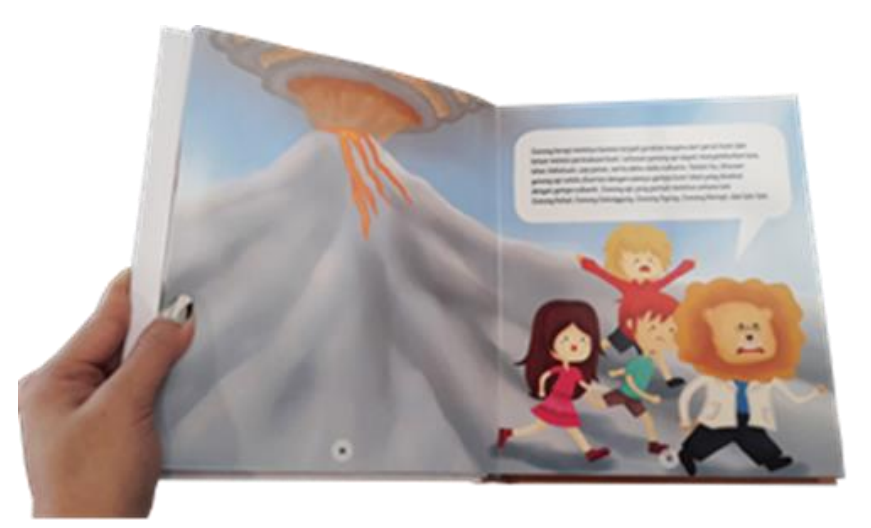

Gambar 10. Simulasi buku ketiga

Sumber: Dokumentasi Penulis

Media pendukung dirancang bertujuan untuk mendukung dan menambahkan nilai lebih pada buku ensiklopedia ekologi dan lingkungan ini. Berikut adalah beberapa media pendukung:
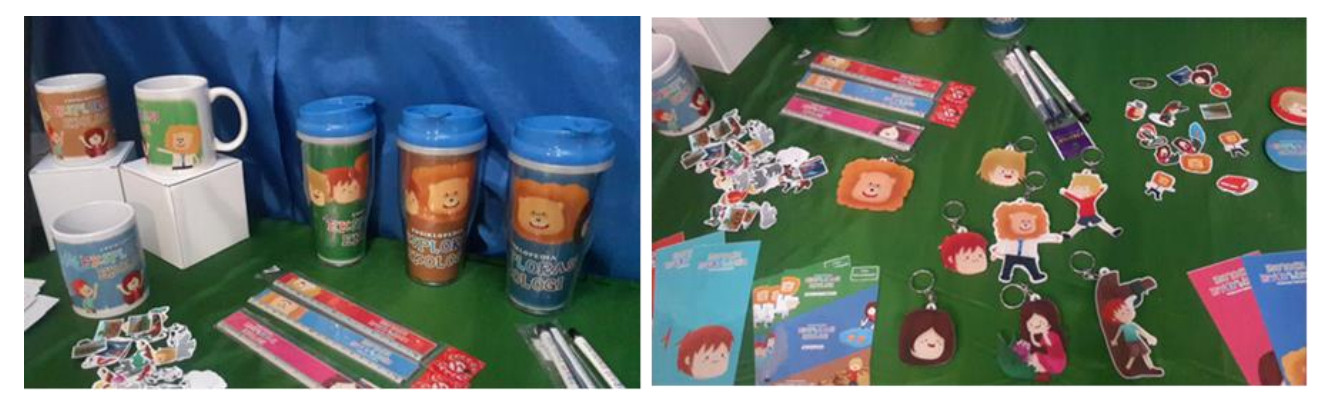

Gambar 11. Media pendukung marchandise Sumber: Dokumentasi Penulis 

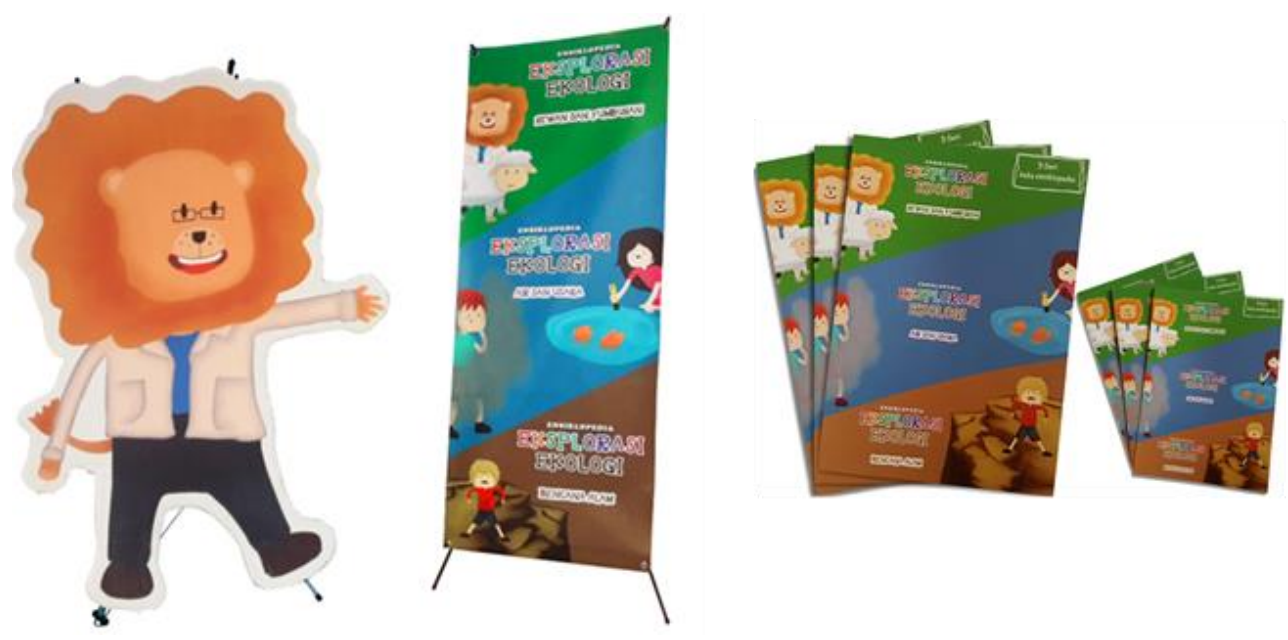

\section{Gambar 12. Media pendukung promosi}

Sumber: Dokumentasi Penulis

\section{SIMPULAN DAN SARAN}

\section{Simpulan}

Perkembangan buku ensiklopedia mulai banyak dengan gaya gambar, layout dan ilustrasi. Namun untuk ensiklopedia dengan penjelasan, gambar dan cerita yang simple dan menarik masih sangat jarang dijumpai. Untuk itu penulis melakukan penelitian melalui wawancara, penyebaran kuesioner, buku literatur, internet dan observasi mengenai buku ensiklopedia ekologi dan lingkungan tersebut.

Dari penelitian tersebut, maka dapat ditemukan hasil kepada penulis untuk melakukan perancangan buku ensiklopedia ekologi dan lingkungan mengenai manusia dan lingkungannya untuk anak usia 9-12 tahun dengan ilutrasi, cerita dan penjelasan yang akan mudah dipahami oleh anak. Hal ini bertujuan untuk menarik minat anak-anak dalam membaca buku, khususnya untuk buku pengetahuan mengenai ekologi dan lingkungan. Buku ini dapat menjadi pedoman bagi orang tua dalam melakukan pembelajaran di rumah. Diharapkan dengan adanya buku ensiklopedia ini dapat menumbuhkan pengertian dan pemahaman anak terhadap lingkungan. Dengan adanya pengertian dan pemahaman itulah tumbuh rasa kecintaan dan kepedulian terhadap ekologi dan lingkungan sekitar. 


\section{Saran}

Penulis menyarankan kepada orang tua untuk membimbing anak-anak dalam mengajarkan betapa pentingnya hubungan timbal balik antara makhluk hidup, untuk lebih memiliki rasa kecintaan dan kepedulian terhadap lingkungan dengan begitu dari masa dini hingga lanjut usia dapat selalu menjaga lingkungan sekitar. Lalu penulis juga menyarankan kepada sekolah-sekolah untuk menyediakan beberapa buku ensiklopedia lingkungan dengan tampilan yang menarik untuk anak-anak, dan guru-guru dapat mencoba metode-metode yang menarik dalam belajar mengajar dengan cara menceritakan melalui buku ensiklopedia dan menunjukkan tempat-tempat yang unik yang dapat menjadi contoh dalam ekologi dan lingkungan kehidupan sekitar.

Saran terakhir yang diberikan penulis kepada mahasiswa dan pembaca yang ingin mencoba membuat karya yang sama diperlukan ketelitian dalam memilih sumber yang tepat untuk dijadikan rujukan pada buku pengetahuan yang akan diberikan kepada target. Diperlukannya kejelian, serta kesabaran, baik dalam perihal mengerjakan laporan maupun proses pembuatan karya. Dalam proses pengerjaan laporan perancangan ini masih terdapat banyak kekurangan tetapi penulis berharap laporan perancangan ini dapat membantu para anak, orang tua, guru, mahasiswa serta pembaca yang ingin melakukan sebuah perancangan yang sama.

\section{DAFTAR PUSTAKA}

Ahira, Anne. (tanpa tahun). Pengertian dan Perkembangan Ensiklopedia. Diakses pada tanggal 6 Maret 2016 dari http://anneahira.com/ensiklopedia.htm/.

Odum, E. P. (1993). Dasar-dasar Ekologi Edisi Ketiga. Yogyakarta: Universitas Gajah Mada Press.

Ramli, Dzaki. (1989). Ekologi. Jakarta: Departemen Pendidikan Kebudayaan Direktorat Jenderal Pendidikan Tinggi.

Supardi, Bahrudin. (2009). Berbakti Untuk Bumi Bandung: Rosdakarya.

Tim Penyusun Kamus Pusat Bahasa (2005). Kamus Besar Bahasa Indonesia. Jakarta: Balai Pustaka. 